\title{
Secondary oesophageal peristalsis in patients with non-obstructive dysphagia
}

\author{
M N Schoeman, R H Holloway
}

\begin{abstract}
Secondary peristalsis was investigated in 30 patients with non-obstructive dysphagia and 20 age matched controls. Oesophageal motility was recorded at $3 \mathrm{~cm}$ intervals along the oesophageal body. Primary peristalsis was tested with $5 \mathrm{ml}$ water swallows. Secondary peristalsis was stimulated with $10 \mathrm{ml}$ boluses of air and water injected in the midoesophagus and by distensions ( 5 seconds duration) with a $3 \mathrm{~cm}$ balloon at the same level. Primary peristalsis was normal in 19 of the 20 control subjects and in nine of the 30 patients with dysphagia; 11 patients had diffuse spasm and 10 had non-specific abnormalities of primary peristalsis. Secondary peristalsis was triggered significantly less frequently by air and water distension in dysphagia patients (median success rate of $10 \%$ for the air boluses and $0 \%$ for the water boluses) than in control subjects $(50 \%$ and $30 \%$ respectively, $p<0.005)$, and was abnormal in six of nine patients with normal primary peristalsis, nine of 11 patients with diffuse spasm and eight of 10 patients with non-specific motor abnormalities. The median frequency of balloon induced secondary peristalsis, however, was not significantly different in the two groups $(0 \%$ controls, $40 \%$ non-

symptom that suggests impaired transport of a swallowed bolus along the oesophagus. In patients with non-obstructive dysphagia, there is no evidence of mechanical obstruction and the symptoms are usually attributed to oesophageal motor dysfunction. ${ }^{1}$ In a significant proportion of these patients, however, routine manometric assessment fails to show any abnormality of primary peristalsis and the aetiology of the symptoms is unclear. $^{1-5}$ Additional tests such as radionuclide measurement of oesophageal transit ${ }^{67}$ or using solid boluses as a part of the manometric assessment may improve the diagnostic findings ${ }^{8-11}$ but the mechanism of the delayed oesophageal transit or clearance detected by these methods is often not explained. The implication, however, is that there is an undetected oesophageal motor abnormality. A possible explanation for these findings is an abnormality of secondary peristalsis. Abnormal oesophageal motor responses to prolonged balloon distension have been reported in patients with non-obstructive dysphagia and it has been suggested that this abnormality contributes to the pathogenesis of the symptoms. ${ }^{12} 13$ The secondary peristaltic responses triggered by oesophageal distension in these patients, however, have not been studied. This study aimed to examine the triggering, integrity, and characteristics of secondary peristalsis in patients with nonobstructive dysphagia.
\end{abstract} obstructive dysphagia, $p=0 \cdot 22$ ). For each stimulus, there were no significant differences in the response rate in the three subgroups of patients. The major pattern of failure of secondary peristalsis in response to the air and water boluses was the complete absence of any oesophageal response. The amplitude of complete secondary peristalsis triggered by the water boluses and the balloon was greater in the patients with dysphagia $(p=0 \cdot 03)$ than in normal subjects, while the amplitude of the secondary peristaltic responses triggered by the air boluses was similar in the two groups. Secondary peristaltic velocity was also similar in normal subjects and patients with nonobstructive dysphagia. Patients with non-obstructive dysphagia show a noticeable defect in the triggering of secondary peristalsis which may make an important contribution to the delayed oesophageal bolus transit and dysphagia seen in this condition.

(Gut 1994; 35: 1523-1528)

Oesophageal dysphagia is an important

\section{Methods}

\section{SUBJECTS}

We studied 30 patients with non-obstructive dysphagia (17 women and 13 men), ranging in age from $26-74$ years (median 59.5 years). All complained of dysphagia as their predominant symptom but nine patients also had chest pain. Mechanical obstruction was excluded in all patients by either endoscopy $(n=29)$ or barium swallow $(n=26)$, or both. Patients taking medication that might affect oesophageal motility were asked not to take this from at least 48 hours before the study.

Twenty age matched healthy subjects (eight women and 12 men), ranging in age from 23-76 years (median 50 years) served as controls. Subjects were free of gastrointestinal symptoms, had no history of upper gastrointestinal surgery, and were not taking antacids regularly or any medication known to change oesophageal motor function. All patients and volunteers gave written informed consent and the study was approved by the Human Ethics Committee of the Royal Adelaide Hospital. 


\section{MANOMETRY}

Oesophageal motility was recorded with a 13 lumen manometric assembly made from a $4.5 \mathrm{~mm}$ diameter silicon rubber extrusion that incorporated a $6 \mathrm{~cm}$ sleeve sensor. Side holes, spaced $3 \mathrm{~cm}$ apart, recorded pressures from seven sites along the oesophageal body starting at $2 \mathrm{~cm}$ above the proximal margin of the lower oesophageal sphincter. A side hole in the gastric fundus recorded gastric pressure and a side hole in the pharynx monitored swallowing. A $3 \mathrm{~cm}$ long silicon rubber balloon, which fitted tightly around the catheter assembly when deflated provided focal distension $12.5 \mathrm{~cm}$ above the lower oesophageal sphincter. An infusion port was located immediately above the balloon for the rapid injection of boluses of air or water. The catheter was fixed and maintained in position so that the mid portion of the sleeve sensor was located within the lower oesophageal sphincter. The oesophageal and gastric side holes and the sleeve sensor were perfused with degassed distilled water at $0.6 \mathrm{ml} /$ minute by a low-compliance pneumohydraulic capillary infusion system. ${ }^{14}$ The pharyngeal side hole was perfused at $0.3 \mathrm{ml} / \mathrm{minute}$. Pressures were sensed by external pressure transducers (Deseret Medica Inc, Park Davis \& Co, Sandy, Utah, USA; model 38-8000-1) with output to a 12 channel polygraph recorder (Grass Instrument Co, Quincy, MA, USA; model 7D). Recordings were made at a paper speed of $5 \mathrm{~mm} / \mathrm{sec}$.

\section{STUDY PROTOCOL}

Subjects were studied after an overnight fast. The catheter was passed pernasally. After a 10 minute adaptation period, both primary and secondary peristalsis were tested in each subject.

Primary peristalsis was tested with $10,5 \mathrm{ml}$ water swallows. Each swallow was separated by an interval of 30 seconds. Secondary peristalsis was triggered by oesophageal distension with $10 \mathrm{ml}$ boluses of air and water and by inflating the intraoesophageal balloon. Each stimulus was tested five times. Balloon distension was performed in only 23 of the 30 patients because of technical problems such as balloon rupture or intolerance of balloon distension due to chest discomfort. The air and water boluses were rapidly injected through the infusion port by hand. The $10 \mathrm{ml}$ air bolus was injected within 0.5 second, while the $10 \mathrm{ml}$ water bolus was delivered within 1.5 seconds. The balloon was inflated with $17 \mathrm{ml}$ of air within 0.5 seconds to a diameter of $3 \mathrm{~cm}$ and sustained for 5 seconds before being quickly deflated over 0.5 seconds. The distending stimuli were given at least 15 seconds after any preceding primary peristaltic wave, and an interval of 20 seconds was allowed after each stimulus for any response to occur. This interval was selected as it is comparable to the latency of the secondary peristaltic response after physiological reflux events. ${ }^{15}$ During this time the subjects were instructed not to swallow. At the end of the 20 second period the subject was asked to perform a dry swallow that served to reduce the desire of the subject to swallow during the distension stimulus as well as to clear any residual air or water.

\section{DATA ANALYSIS}

The contraction amplitude at each recording site and the latency of the wave onset between adjacent recording sites were determined for both primary and secondary peristalsis. Amplitude was measured from basal endexpiratory intraoesophageal pressure to the peak of the pressure wave. The onset of the major upstroke of the pressure wave was used as the reference point for determination of the wave latency.

Primary peristalsis was classified as complete if a propagated pressure wave of $\geqslant 12 \mathrm{~mm} \mathrm{Hg}$ at the proximal two oesophageal recording sites and $\geqslant 25 \mathrm{~mm} \mathrm{Hg}$ in the distal five oesophageal channels, traversed all the recording sites. ${ }^{1617}$ The minimum latency of wave onset between adjacent recording sites that defined peristaltic progression was set at 0.5 seconds, corresponding to a peristaltic velocity of $6 \mathrm{~cm} / \mathrm{sec}^{17}$ Criteria for failed peristalsis were either failure of a pressure wave $\geqslant 12 \mathrm{~mm} \mathrm{Hg}$ in the proximal two recording sites and $\geqslant 25 \mathrm{~mm} \mathrm{Hg}$ in the distal five channels to traverse all of the oesophageal recording sites or synchronous pressure waves occurring at two or more recording sites. In addition, no response to distension was judged to have occurred if a pressure wave $\geqslant 10 \mathrm{~mm} \mathrm{Hg}$ was seen in less than two recording sites. For complete peristaltic responses, mean amplitude and velocity were calculated for the five distal recording sites corresponding to the distal $12 \mathrm{~cm}$ of the smooth muscle segment of the oesophageal body. Normal primary peristalsis was defined as the occurrence of eight or more complete peristaltic responses to the 10 water swallows. ${ }^{18}$

Secondary oesophageal motor responses to air and water boluses were typically characterised by a propagated pressure wave that traversed the entire oesophagus, ${ }^{19}$ and were analysed according to the criteria given above for primary peristalsis. The response to balloon distension, however, was different from the response triggered by the air and water injections as there were separate responses above and below the balloon. ${ }^{19}$ During balloon inflation, a sustained pressure wave was seen above the balloon with inhibition of motor activity below. After balloon deflation, the pressure wave above the balloon subsided and a motor response was seen below the balloon. Each component of the balloon response was analysed individually using the same criteria as for primary peristalsis. ${ }^{19}$

\section{STATISTICAL ANALYSIS}

The frequencies of successful primary and secondary peristalsis were determined for each stimulus in each subject. Differences 


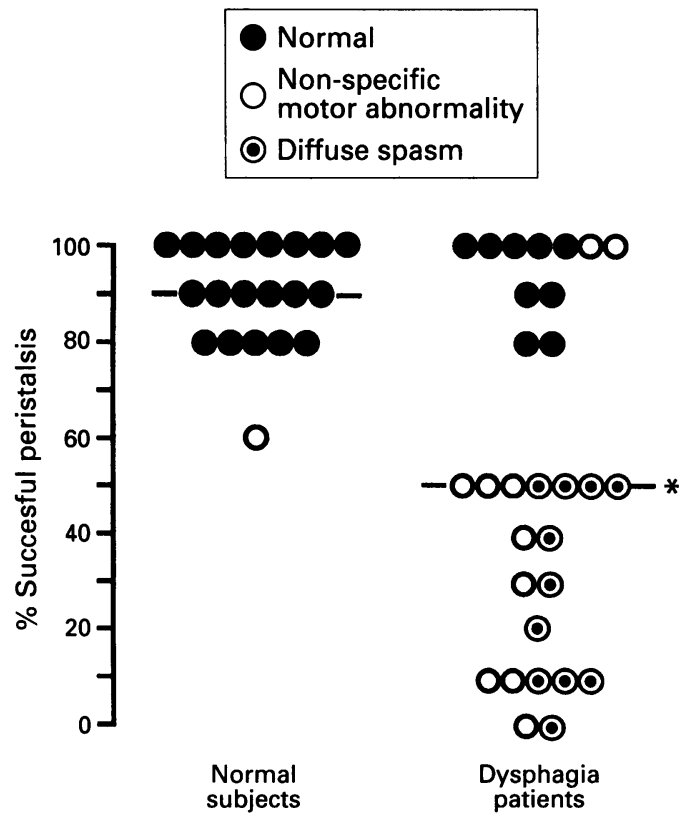

Figure 1: The percentage of complete primary peristaltic responses for each subject. The horizontal bars indicate the median values. ${ }^{\star} p=0.001 \mathrm{v}$ normal subjects.

in response rates among stimuli were analysed using log linear modelling techniques $^{20}$ and non-parametric tests for paired and unpaired data. Data for peristaltic amplitude and velocity and the pattern of oesophageal motor responses to distension were pooled and subjected to analysis of variance. ${ }^{21}$ Group data for response rates are expressed as median values (interquartile range) and those for peristaltic amplitude and velocity as mean (SEM).
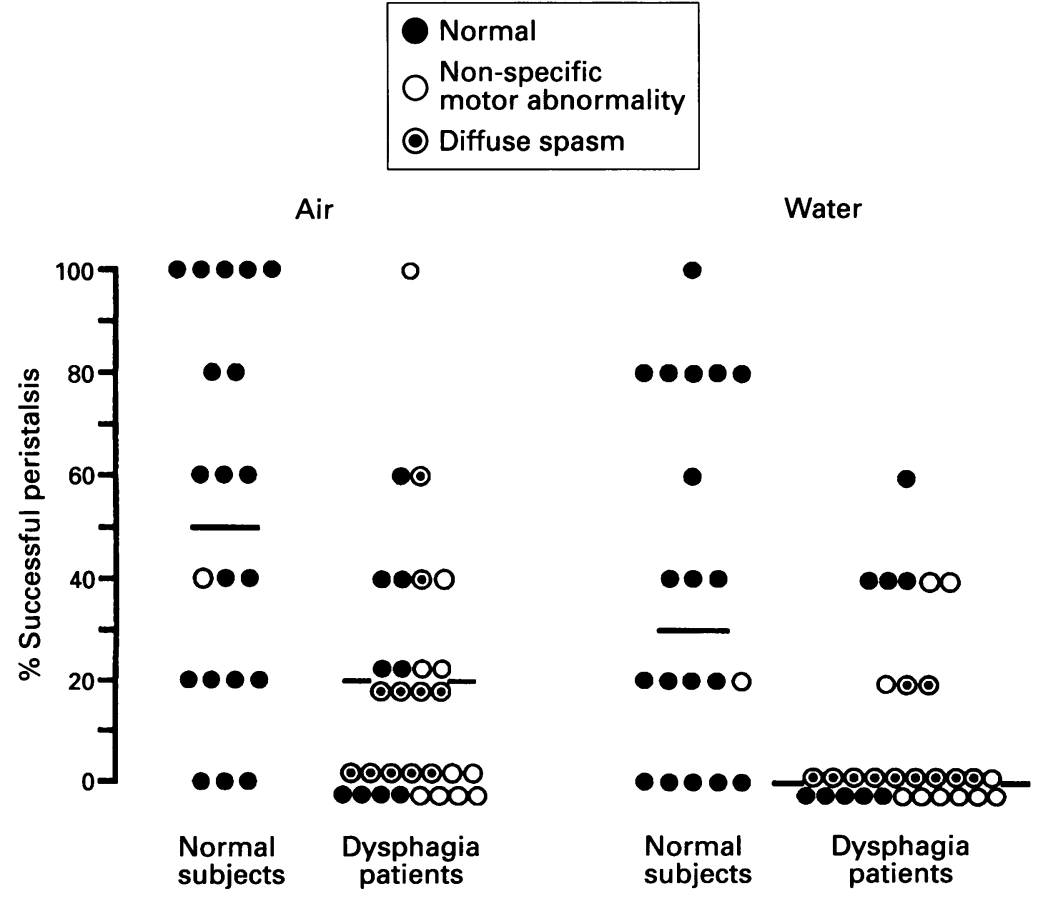

Figure 2: Percentage of secondary peristalsis with air and water boluses. Each point represents the proportion of normal secondary peristaltic responses (out of five tests) for each subject. The horizontal bars indicate the median values. ${ }^{\star} p=0.003 \mathrm{v}$ normal.
Peristaltic amplitude and velocity (values mean (SEM))

\begin{tabular}{|c|c|c|}
\hline & $\begin{array}{l}\text { Normal } \\
\text { subjects }\end{array}$ & $\begin{array}{l}\text { Non-obstructive } \\
\text { dysphagia patients }\end{array}$ \\
\hline $\begin{array}{l}\text { Amplitude (mm Hg): } \\
\text { Primary peristalsis } \\
\text { Secondary peristalsis }\end{array}$ & $80 \cdot 6(2 \cdot 1)$ & $94 \cdot 6(3 \cdot 3) t$ \\
\hline Air & $77 \cdot 1(3 \cdot 5)$ & $83.3(9 \cdot 0)$ \\
\hline Water & $73 \cdot 2(3 \cdot 2)$ & $87 \cdot 4(6 \cdot 5) \ddagger$ \\
\hline Balloon* & $68 \cdot 1(3 \cdot 2)$ & $94 \cdot 0(6 \cdot 6) \oint$ \\
\hline Velocity $(\mathrm{cm} / \mathrm{s})$ : & & \\
\hline $\begin{array}{l}\text { Primary peristalsis } \\
\text { Secondary peristalsis }\end{array}$ & $2 \cdot 8(0.04)$ & $2.9(0.06)$ \\
\hline Air & $2.9(0.08)$ & $2.8(0.15)$ \\
\hline Water & $2 \cdot 6(0 \cdot 11)$ & $2 \cdot 5(0 \cdot 17)$ \\
\hline Balloont & $2 \cdot 7(0 \cdot 19)$ & $3 \cdot 2(0 \cdot 14)$ \\
\hline
\end{tabular}

* Secondary peristaltic responses induced by balloon distension occurred below the balloon after deflation.

$\mathrm{tp}=0.0003 v$ normals.

$\neq \mathrm{p}=0.03 v$ normals.

$\mathrm{\rho}=0.005 v$ normals.

\section{Results}

PRIMARY PERISTALSIS

The rate of successful primary peristalsis was significantly lower in the patients with dysphagia $(50 \%(29-90 \%))$ than in the normal subjects $(90 \%(80-100 \%), \mathrm{p}<0.005)$. Nineteen of the 20 normal subjects and nine $(30 \%)$ of the 30 dysphagia patients exhibited normal primary peristalsis (Fig 1). Conversely, 21 (70\%) of the 30 dysphagia patients had abnormal primary peristalsis, with a median response rate in this group of $40 \%(10-50 \%)$. Eleven of the 21 patients were diagnosed as having diffuse oesophageal spasm and eight had non-specific motor abnormalities including two with high amplitude peristaltic contractions in the distal oesophagus. ${ }^{22}$ The mean contraction amplitude and propagation velocity for the primary peristaltic responses are summarised in the Table. Peristaltic amplitude was greater in the patients with dysphagia than the normal volunteers $(p<0.0005)$ but the primary peristaltic velocities were similar in the two groups $(p=0 \cdot 7)$.

\section{SECONDARY PERISTALSIS}

Air and water boluses

Peristaltic response rates to air boluses were significantly lower in the patients with dysphagia as a group $(10 \%(0-20 \%))$ than in the normal subjects $(50 \%(20-90 \%), \mathrm{p}<0.002)$ (Fig 2). Response rates in the subgroups of patients with normal primary peristalsis $(20 \%$ $(0-40 \%))$, diffuse spasm $(20 \%(0-20 \%))$, and non-specific motor abnormalities (0 (0-20\%)) were not statistically different and were each less than that in normal subjects. Using the fifth centile $(20 \%)$ as the lower limit of normal, secondary peristaltic responses to air were abnormal in six of nine patients with normal primary peristalsis, nine of 11 patients with diffuse spasm, and eight of 10 patients with nonspecific motor abnormalities.

Water boluses produced similar results with a median response rate of $0 \%(0-20 \%)$ in patients with dysphagia compared with $30 \%$ $(10-80 \%)$ in the normal subjects $(p<0.005)$. Response rates in the subgroups of patients with diffuse spasm $(20 \%(0-20 \%))$ and nonspecific motor abnormalities (0\% (0-20\%)) 


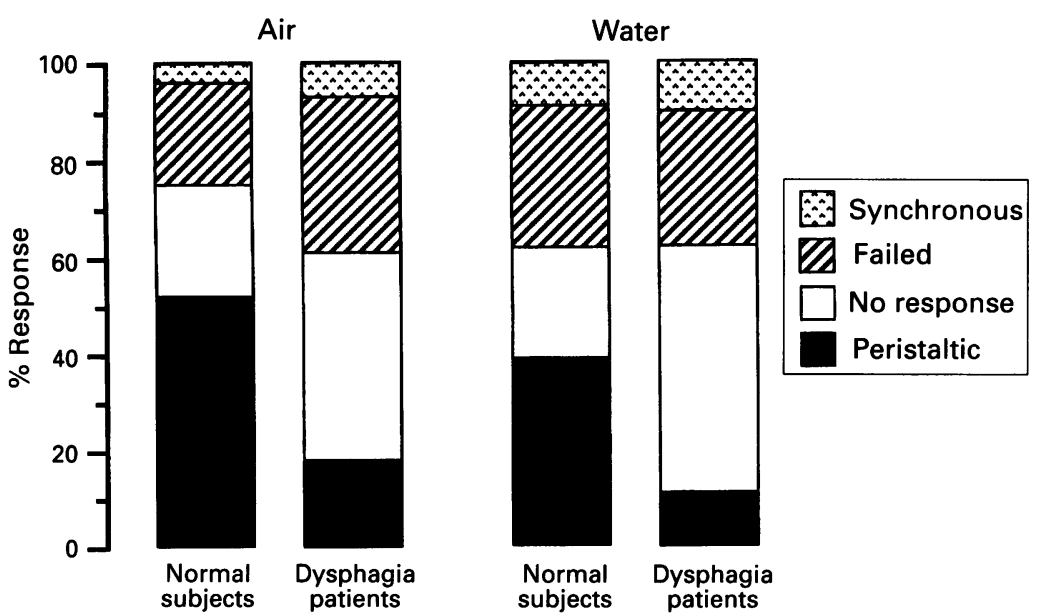

Figure 3: Patterns of manometric response to $10 \mathrm{ml}$ boluses of air and water. The proportions of the various patterns of manometric response are derived from pooled data of the individual responses.
The pattern of the motor responses for the air and water boluses are shown in Figure 3. In the normal subjects, $52 \%$ of the air boluses triggered a peristaltic response while $21 \%$ failed to trigger any response at all. A small proportion of air boluses triggered failed or synchronous responses. In the patients with dysphagia, however, only $18 \%$ of air boluses triggered secondary peristalsis and $43 \%$ produced no response. The proportion of failed and synchronous responses were similar in the patients and controls, and among the three subgroups of patients. Water boluses resulted in a similar patterns of responses in the two groups.

\section{Balloon distension}

The frequency of secondary peristaltic responses seen distal to the balloon after deflation is shown in Figure 4. The response rate below the balloon varied widely among subjects and the mean (SEM) values in the patients with dysphagia $(20 \%(0-60 \%))$ were not statistically different from those in the normal subjects $(0 \%(0-70 \%) ; p=0 \cdot 22)$. In the normal subjects, the response rate to balloon distension was significantly less than that for the air boluses $(p<0.04)$ but similar to that for the water boluses. In the dysphagia patients, the secondary peristaltic response rate to balloon distension was greater than that for air $(p<0.05)$ and water boluses $(p<0.004)$.

The contraction amplitude of secondary peristalsis elicited by balloon distension was greater in the dysphagia patients than the normal subjects $(p=0.005)$ while the propagation velocities were similar in the two groups (Table).

The pattern of balloon responses are shown in Figure 5. There were no significant differences in the proportions of the motor responses either above or below the balloon between the two groups nor among the three subgroups of patients.

\section{Discussion}

Non-obstructive dysphagia is a common indication for referral for oesophageal manometry as it is generally believed to be a result of oesophageal motor dysfunction. ${ }^{1}$ In a significant proportion of patients, however, manometric assessment of primary peristalsis fails to reveal any abnormality and the cause of the symptoms remains unclear. ${ }^{1-5}$ One possible explanation for this discrepancy is that testing of primary peristalsis is not sufficiently sensitive to detect subtle oesophageal motor abnormalities. This notion is supported by several studies showing radiological and scintigraphic abnormalities in patients with dysphagia and normal primary peristalsis. ${ }^{6-11}$

Abnormal secondary oesophageal peristalsis is a potential mechanism that might account for these discrepancies, as secondary peristalsis is an important mechanism of oesophageal volume clearance. ${ }^{2324}$ This study is the first assessment of secondary peristalsis in patients with non-obstructive dysphagia and shows that they commonly have defective secondary 


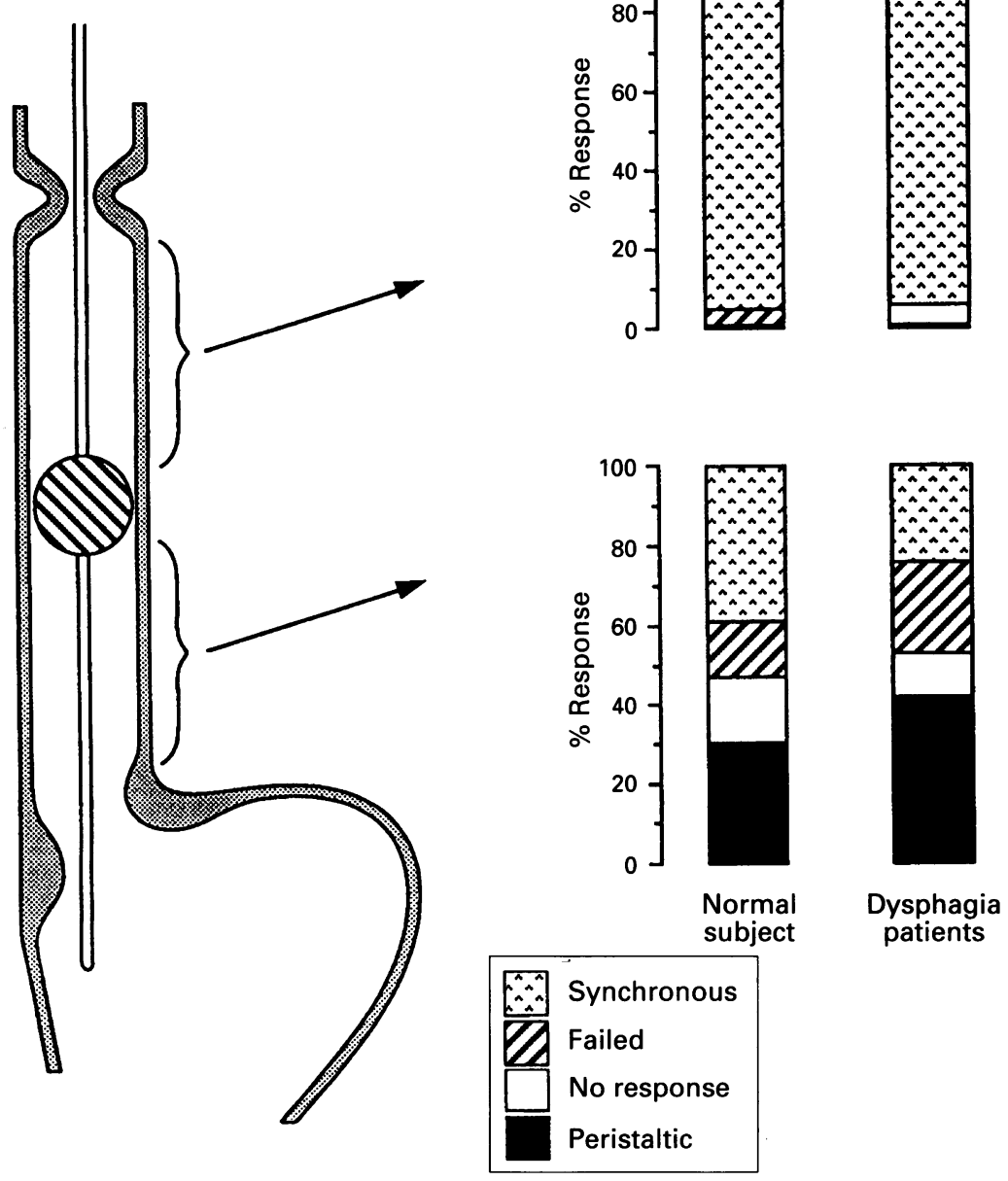

Figure 5: Patterns of manometric response to balloon distension. The proportion of various patterns of manometric response are derived from pooled data of the individual responses. Responses have been divided into those occurring above and below the balloon. The responses above the balloon occurred during inflation and those below the balloon occurred after deflation. The patterns of response were similar in the two groups.

peristalsis in response to oesophageal distension with boluses of air and water. The inference from this result is that the patients will similarly fail to respond to the distension induced by a retained bolus in the oesophagus and that this may be an important mechanism in the development of their symptoms. Standard manometric assessment of primary peristalsis detected an abnormality in $63 \%$ of our patients but when the secondary peristaltic responses to air and water boluses were also considered, the proportion of patients with abnormal oesophageal motor function increased to $80 \%$.

The patients with dysphagia in this study comprised a heterogeneous group including those with normal primary peristalsis, those with diffuse spasm and patients with nonspecific motor abnormalities. Nevertheless, secondary peristalsis response rates and the proportion of patients with defective secondary peristalsis were similar in the three subgroups suggesting that they share a common defect in triggering of secondary peristalsis. While abnormal secondary peristalsis might be expected in patients with abnormal primary peristalsis the finding of abnormal responses in patients with normal primary peristalsis indicates a specific abnormality of secondary peristalsis and a potential contributor to the pathogenesis of dysphagia in this subgroup of patients.

The mechanisms underlying defective secondary peristalsis in response to the air and water injection remain to be defined, but inferences are possible from the pattern of the responses and previous observations. As secondary peristalsis is a reflex response to oesophageal distension, the defect may lie either in the oesophageal motor nerve supply or muscles, or in oesophageal sensation, or perhaps both. In patients with abnormal primary peristalsis, it is possible that there is a defect in the efferent limb of the reflex arc, although the pattern of abnormal primary peristalsis did not have any significant bearing on the pattern of abnormal secondary peristalsis. Interestingly, in our study some patients with abnormal primary peristalsis had normal secondary peristalsis suggesting that the defect in primary peristalsis in these patients lies in the central control mechanisms rather than in the peripheral neural pathways or oesophageal muscle. In patients with both abnormal primary and secondary peristalsis, however, the defect is more difficult to localise.

In patients with normal primary peristalsis and abnormal secondary peristalsis, the efferent pathways seem to be intact and this suggests that there is a defect in the afferent limb of the reflex pathway with impaired oesophageal sensitivity to distension. This hypothesis has not been examined in patients with non-obstructive dysphagia. In patients with oesophagitis, however, Williams et al noted that the distension threshold required to trigger a motor response to prolonged oesophageal distension was higher than that in healthy controls. ${ }^{25}$ Deschner et al have reported that the distension threshold for symptoms was lower in patients with nonobstructive dysphagia ${ }^{12}$ but the volume required to elicit symptoms has been shown to be different from the volume required to trigger an oesophageal motor response. ${ }^{25}$

Secondary peristaltic responses to balloon distension were not significantly different between normal subjects and patients with dysphagia. This was due largely to a low response rate in the normal subjects. We observed similar findings in a study of secondary peristalsis in gastro-oesophageal reflux disease ${ }^{19}$ and this supports our conclusion from other studies ${ }^{19} 26$ that balloon distension is an ineffective method of testing secondary peristalsis. The apparent discrepancy between the balloon responses and those to air and water boluses most likely reflects differences in the nature of the distending stimulus, the balloon providing a focal and fixed distension in contrast to the more diffuse and mobile stimulus with air and water boluses.

Although secondary peristalsis has not been formally examined in patients with nonobstructive dysphagia, recent studies have shown that oesophageal motor responses to prolonged distension are abnormal in these patients. ${ }^{12} 13$ These studies showed abnormal 
contractions in the distal oesophagus during balloon inflation in patients with non-obstructive dysphagia while the motor responses proximal to the balloon were similar to those in normal subjects. We also noted similar patterns of motor activity above the balloon in the normal subjects and the patients, but failed to detect any motor activity in the distal oesophagus during balloon inflation. A possible explanation may be the greater balloon diameter used in our study leading to a greater degree of distal inhibition. Alternatively, we used sudden and relatively brief balloon distension rather than gradual distension (1 $\mathrm{ml} / 3 \mathrm{sec}$ ) which may have influenced the pattern of the response.

Evaluation of the manometric characteristics of the secondary peristaltic responses showed a higher mean peristaltic amplitude in the patients with non-obstructive dysphagia than in the normal volunteers, while the propagation velocity in the two groups was similar. The importance of this finding is not clear but it is interesting to note that a similar difference is seen for primary peristaltic amplitude and perhaps reflects a generally increased oesophageal contractile strength. Similar results were reported by Jacob et al who found higher primary peristaltic amplitudes in patients with dysphagia than in patients without dysphagia. ${ }^{1}$

In summary, we have shown a noticeable defect in secondary peristalsis in patients with dysphagia. This defect may well result in delayed bolus transit along the oesophagus and contribute to the development of the patient's symptoms. Examination of secondary peristalsis may be useful in the diagnostic evaluation of patients with non-obstructive dysphagia.

This project was supported by a project grant from the National Health and Medical Research Council. Dr Schoeman is supported by a National Health and Medical Research Council Postgraduate Scholarship and a Royal Adelaide Hospital Dawes Scholarship. The valuable support and assistance of Professor Scholarship. The valuable support and assistance of Professor John Dent in the development of the recording apparatus and for reviewing the manuscript is gratefully acknowledged. The
authors also thank Mr Marcus Tippett for his technical support authors also thank Mr Marcus Tippett for his technical support
and assistance. This study was presented at The American and assistance. This study was presented at The American Orleans, May 1991 and published in abstract form in Gastroenterology May 1991.

1 Jacob P, Kahrilas P, Vanagunas A. Peristaltic dysfunction associated with nonobstructive dysphagia in reflux associated with nonobstructive dys

2 Barish CF, Castell DO, Richter JE. Graded esophageal balloon distension. A new provocative test for noncardiac chest pain. Dig Dis Sci 1986; 31: 1292-8.
3 Katz PO, Dalton CB, Richter JE, Wu WC, Castell DO Esophageal testing of patients with noncardiac chest pain or dysphagia - results of three years' experience with 1161 or dysphagia - results of three years' expe

4 Ott DJ, Richter JE, Chen YM, Wu WC, Gelfand DW, Castell DO. Esophageal radiography and manometry: correlation in 172 patients with dysphagia. $A m \quad \mathcal{J}$ Roentgenol 1987; 149: 307-11.

5 Triadafilopoulos G. Nonobstructive dysphagia in reflux esophagitis. Am $\mathcal{F}$ Gastroenterol 1989; 84: 614-18.

6 Russell C, Hill L, Holmes E, Hull D, Gannon R, Pope C. Radionuclide transit: A sensitive screening test fo esophageal dysfunction. Gastroenterology 1981; 80: 887-92.

7 Kjellén G, Svedberg JB, Tibbling L. Solid bolus transit by oesophageal scintigraphy in patients with dysphagia and normal manometry and radiography. Dis Dig Sci 1984; 29: $1-5$.

8 Keren S, Argaman E, Golan M. Solid swallowing versus water swallowing: manometric study of dysphagia. Dig Dis Sci 1992; 37: 603-8.

9 Howard P, Pryde A, Heading R. Oesophageal manometry during eating in the investigation of patients with ches pain or dysphagia. Gut 1989; 30: 1179-86.

10 Howard PJ, Maher L, Pryde A, Heading RC. Esophagea motor patterns during episodes of dysphagia for solids. fournal of Gastrointestinal Motility 1991; 3: 123-30.

11 Blackwell J, Hannan W, Adam R, Heading R. Radionuclide transit studies in the detection of oesophageal dysmotility. Gut 1983; 24: 421-6.

12 Deschner WK, Maher KA, Cattau EL, Benjamin SB Manometric responses to balloon distension in patients with nonobstructive dysphagia. Gastroenterology 1989; 97: with non

13 Williams D, Thompson DG, Marples M, O'Hanrahan T, Bancewicz J. Motor responses to mechanoreceptor stimulation in the normal oesophagus and in patients with oesophageal symptoms. Fournal of Gastrointestinal Motility 1990; 2: 163.

14 Arndorfer RC, Stef J, Dodds WJ, Linehan JH, Hogan WJ. Improved infusion system for intraluminal esophageal manometry. Gastroenterology 1977; 73: 23-7.

15 Dodds WJ, Kahrilas PJ, Dent J, Hogan WJ, Kern MK Arndorfer RC. Analysis of spontaneous gastroesophagea reflux and esophageal acid clearance in patients with reflux esophagitis. Fournal of Gastrointestinal Motility 1989; 1: $105-14$.

16 Kahrilas PJ, Dodds WJ, Hogan WJ. Effect of peristaltic dysfunction on esophageal volume clearance. dysfunction on esophageal
Gastroenterology 1988; 94: 73-80.

17 Hewson E, Ott D, Dalton C, Chen Y, Wu W, Richter J. Manometry and radiology. Complementary studies in the assessment of esophageal motility disorders. Gastroenterology 1990; 98: 626-32.

18 Richter JE, Wu WC, Johns DN, et al. Esophageal manometry in 95 healthy adult volunteers. Dig Dis Sci 1987; 32 583-92.

19 Schoeman M, Holloway R. Stimulation and characteristics of secondary oesophageal peristalsis in normal subjects. Gut 1994; 35: 152-8.

20 Bishop YMM, Fienberg SE, Holland PW Discrete multivariate analysis: theory and practise. Cambridge, MA: The MIT Press, 1975

21 Brunning JL, Kintz BL. Computational Handbook of Statistics 3rd ed. Glenview, Illinois: Harper Collins Publishers, 1987. 3rd ed. Glenview, Illinois: Harper Collins Publishers, 1987. 2 Stuart RC, Hennessy TPJ. Primary disorder

23 Helm JF, Dodds WJ, Pelc LR, Palmer DW, Hogan WJ, Teeter BC. Effect of oesophageal emptying and saliva on clearance of acid from the esophagus. N Engl F Med 1984 310: $284-8$

24 Dent J, Dodds WJ, Freidman RH, et al. Mechanism of gastroesophageal reflux in recumbent asymptomatic human subjects. $\mathcal{F}$ Clin Invest 1980; 65: 256-67.

25 Williams $\mathrm{D}$, Thompson DG, Marples $\mathrm{M}$, et al. Identification of an abnormal esophageal clearance response to intraluminal distension in patients with esophagitis. Gastroenterology 1992; 103: 943-53.

26 Schoeman MN, Tippett M, Dent J, Holloway RH. Integrity and characteristics of secondary peristalsis in patients with and characteristics of secondary peristalsis in patients with
gastroesophageal reflux disease [Abstract]. Gastroenterology 1991; 100: A157. 